\title{
TRIPIANA-MUÑOZ, S. (2019) ESTRATEGIAS EFICACES DE PRÁCTICA INSTRUMENTAL. PRIMEROS PASOS AL ESTUDIAR UNA OBRA MUSICAL GRANADA: EDITORIAL LIBARGO
}

ए

\section{Liliana Pignatelli}

Esta monografía aborda el tema de las claves del éxito de los grandes intérpretes de música desde la perspectiva de la importancia del estudio eficaz, estratégico y perseverante.

La autora relata como en tan solo los últimos 100 años, se ha observado un interés científico por la naturaleza de la práctica instrumental y su relación con la transición desde niveles iniciales hasta niveles de excelencia, por medio de un cuerpo creciente de estudios a través de numerosas disciplinas. Sin embargo, existe muy poca literatura al respecto.

El libro consta de los siguientes capítulos:

Capítulo 1. Buscando estrategias de práctica instrumental. En él, la autora expone su relación personal con el tema objeto de estudio y justifica convenientemente el por qué de su investigación. Asimismo, conduce su exposición dando respuesta a algunos grandes interrogantes que sobrevuelan el pensamiento de aquellas personas dedicadas a la interpretación musical: ¿̇e nace con talento musical o es el músico el único responsable de su propio éxito?; cualquier gran instrumentista, ¿̇ha logrado alcanzar su nivel de dominio técnico-interpretativo con menor dedicación que el resto de los mortales?; ¿existen diferencias de género a la hora de llevar a cabo la práctica instrumental? ¿̇para qué practica un pianista, una percusionista o una flautista? ¿Cuál es el propósito principal de sus horas de estudio?

Desde el capítulo 2 hasta el 9, se presentan las ocho estrategias de práctica que van a guiar los primeros pasos al abordar el estudio de una nueva obra musical. Tras su definición, la autora revela investigaciones previas al respecto de cada una de las estrategias; relata cómo llevar a cabo cada estrategia por medio de diferentes propuestas; expone importantes testimonios de uso de cada estrategia por grandes intérpretes de música; y, finalmente, aborda un resumen de cada una de ellas para llevar a la práctica y optimizar el estudio musical más eficazmente.

Capítulo 2. Práctica fragmentada: la estrategia más sencilla. Esta primera propuesta propone una ejecución fragmentada, según criterios musicales, dividiendo la complejidad y alentando a progresar al intérprete desde lo más simple a lo más complejo. 
Capítulo 3. Práctica con máxima concentración: la estrategia más agotadora. En esta propuesta la autora pone de relieve la importancia de la atención plena en la ejecución musical.

Capítulo 4. Adecuación ergonómica: la estrategia más natural. Un relato que pone de manifiesto el cuerpo humano y el uso que se hace del mismo como un ingrediente más de la práctica musical exitosa. En definitiva, hace alusión al funcionamiento cómodo y natural del medio corporal de cualquier instrumentista por medio del movimiento natural, la economía motriz (máximo rendimiento y mínimo esfuerzo), la influencia de la gravedad, integrando la respiración y buscando el apoyo como medio de seguridad.

Capítulo 5. Mensajes de auto-orientación: la estrategia más constructiva. En este capítulo la autora hace un recorrido por el contenido de mensajes de auto ayuda que plantean objetivos durante el estudio, que sirven de auto-guía como mensajes de advertencia, de apoyo o de recuerdo y que efectúan una retroalimentación informativa evaluando los resultados o la misma sesión de práctica.

Capítulo 6. Escucha autocrítica: la estrategia más analítica. Con esta propuesta la autora pone de relieve la importancia de percibir auditivamente cómo cada sonido resuena en el espacio exterior, efectuando una necesaria retroalimentación y pudiendo valerse de la ayuda de medios audiovisuales, principalmente grabaciones de audio y vídeo.

Capítulo 7. Lectura precisa: la estrategia más preventiva. En este caso, propone realizar una lectura precisa de la obra musical objeto de estudio, a modo preventivo, tocando con corrección desde la primera vez, aislando la dificultad, analizando su naturaleza y asumiendo un margen de aceptabilidad sin que la perfección se convierta en obsesión para el intérprete.

Capítulo 8. Práctica indirecta: la estrategia más extendida. Esta repetida propuesta supone alterar el tempo de la interpretación, generando nuevos retos a resolver por la persona que interpreta y acrecentando la dificultad existente en la partitura.

Capítulo 9. Respeto al límite actual: la estrategia más prudente. En este capítulo la autora pretende que cualquier instrumentista efectúe una adaptación a su límite técnico-interpreta- tivo actual con el instrumento, es decir, que no pretenda más de lo que en el momento presente es capaz de realizar.

Capítulo 10. Pasión, perseverancia y... İadelante! Un capítulo final que ilustra a la perfección la importancia del esfuerzo constante, el deseo de conseguir la meta a pesar de los impedimentos y la pasión y la perseverancia que una persona puede llegar a alcanzar en su trabajo musical diario.

El libro concluye con un apartado dedicado a referencias bibliográficas y un exhaustivo índice onomástico.

En definitiva, esta monografía destaca por orientar a los instrumentistas noveles, y/o estudiantes de un grado medio/superior.

Nos queda por saber qué ocurre en el $1^{\circ}$ nivel elemental, cómo fomentar estas estrategias desde el inicio para que al llegar a grados más avanzados, los estudiantes tengan dichas prácticas asimiladas y puedan aplicarlas en obras de mayor dificultad.

Los conservatorios forman instrumentistas, pero no pedagogos. Este libro es una gran oportunidad para guiar a esos instrumentistas que darán clases.

También sería interesante que cada docente haga una reflexión y abra su mente para continuar con su aprendizaje, para luego establecer una vía de comunicación con el alumno, a través de la cual podrá proporcionarle las herramientas necesarias para ayudarlo a encontrar soluciones a sus problemas.

El alumno también forma parte del engranaje que pone en funcionamiento el proceso de enseñanza-aprendizaje y por lo tanto también es responsable de su futuro como profesional. Está en su mano el tener en cuenta los conocimientos y los consejos que les proporcionan sus profesores y sacar el mejor provecho de los mismos.

Por otro lado las instituciones, son el tercer elemento del mecanismo. Sería conveniente que se escuchen las necesidades de los alumnos y profesores. Aunque la formación en las mismas no sea netamente pedagógica, que puedan tener la libertad de poder hacer modificaciones para evolucionar y crear un camino hacia la excelencia. 